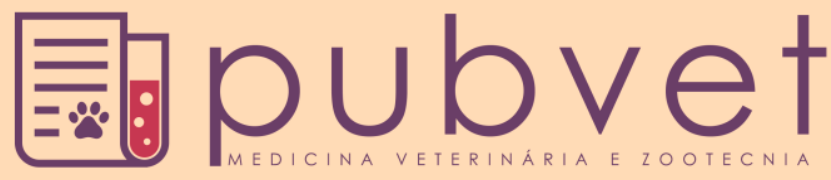

http://dx.doi.org/10.22256/pubvet.v11n1.62-73

\title{
Mastite em rebanhos bubalinos e sua suscetibilidade antimicrobianos
}

\author{
Alan Andrade Mesquita ${ }^{*}$, Geraldo Marcio da Costa ${ }^{2}$, Flavio Vieira Martins de Almeida ${ }^{3}$, \\ Fabiana Alves Demeu ${ }^{4}$, Eduardo Mitke Brandão Reis ${ }^{5}$
}

${ }^{I}$ Zootecnista da Universidade Federal de Lavras, doutorando em Ciências Veterinárias pela Universidade Federal de Lavras, Departamento de Medicina Veterinária. Lavras - MG Brasil. E-mail: alan.mesquita@dzo.ufla.br

${ }^{2}$ Professor da Universidade Federal de Lavras, Departamento de Medicina Veterinária. Lavras-MG Brasil. E-mail: marciocostavet@gmail.com

${ }^{3}$ Químico da Universidade Federal de Lavras, mestrando em Agroquímica pela Universidade Federal de Lavras, Departamento de Química. Lavras -MG, Brasil. E-mail: flavioalmeida@dzo.ufla.br

${ }^{4}$ Professora do Instituto Federal de Educação, Ciências e Tecnologia de Rondônia, doutoranda em Ciências Veterinárias pela Universidade Federal de Lavras, Departamento de Medicina Veterinária.Lavras-MG Brasil.E-mail:fabiana.alves@ifro.edu.br

${ }^{5}$ Professor Universidade Federal do Acre, doutorando em Ciências Veterinárias pela Universidade Federal de Lavras, Departamento de Medicina Veterinária. Lavras-MG Brasil. E-mail: $\underline{\text { edumitke@gmail.com }}$

*Autor para correspondência

RESUMO. O objetivo deste estudo foi verificar os principais patógenos causadores da mastite em rebanhos de búfalas, correlacionar a presença destes patógenos com os índices de qualidade de leite e avaliar o perfil de suscetibilidade dos microrganismos encontrados aos principais antibióticos utilizados no controle da mastite, e também elucidar quais os fatores de risco presentes nas propriedades na qual há presença da mastite. Os resultados demonstraram que a mastite é a principal doença infecciosa, e que traz grandes perdas na produtividade individual, e uma das possibilidades para os índices de produção individual das búfalas serem abaixo do esperado, pode estar correlacionada com a presença desta doença nos rebanhos de bubalinos do Brasil.

Palavras chave: Búfalas, contagem de células somáticas, contagem bacteriana total, leite

\section{Mastitis in buffalo herds and their susceptibility to antimicrobial}

ABSTRACT. The aim of this study was to determine the main pathogens causing mastitis in buffalo herds, correlate the presence of these pathogens in the milk quality indicators and assess the microorganism susceptibility profile found to the main antibiotics used in the control of mastitis, and also elucidate which risk factors present in the properties in which there is the presence of mastitis. The results demonstrated that mastitis is the major infectious disease, which brings great loss in individual productivity, and the possibilities for individual production rates of buffaloes are lower than expected can be correlated with the presence of the disease in herds of buffalo of Brazil.

Keywords: Buffalo, somatic cell count, total bacterial count, milk

\section{Mastitis en búfalos y susceptibilidad a los antimicrobianos}

RESUMEN. El objetivo de este estudio fue verificar los principales patógenos causadores de mastitis en rebaños de búfalas, correlacionar la presencia de estos patógenos con los índices de calidad de leche y evaluar el perfil de susceptibilidad de los microrganismos encontrados a los principales antibióticos utilizados en el control de mastitis, y también elucidar los factores de riesgo presentes en las propiedades en las cuales hay presencia de la mastitis. Los resultados demuestran que la mastitis es la principal enfermedad infecciosa, y que trae grandes pérdidas en la productividad individual, y una de las posibilidades para 
los índices de producción individual de las búfalas ser abajo de lo esperado, puede estar correlacionada con la presencia de esta patología en los rebaños de bufalinos del Brasil.

Palabras clave: Búfalas, contaje de células somáticas, contaje bacteriana total, leche

\section{Introdução}

A cadeia produtiva do leite de búfalas e seus derivados vêm ganhando mais força todos os anos, com crescimento acima do setor de produção de leite de bovinos. Mas com esse crescimento vêm surgindo problemas que antes não se observava, na qual a mastite nas búfalas se encaixa. Até pouco tempo atrás era usado este animal somente para tração e produção de carne. Atualmente com o melhoramento genético voltado para a busca de búfalas com aptidão leiteira começaram a surgir problemas sanitários, que seria o caso da mastite. Como não se tem uma base de conhecimento específico para as búfalas adotam-se as medidas sanitárias utilizadas para vacas leiteiras, o que pode trazer graves problemas sanitários, pois se trata de animais totalmente distintos.

A busca por dados quantitativos e qualitativos sobre a ocorrência da mastite em búfalas e os fatores de risco associados à mastite, é necessária para que se amplie o conhecimento epidemiológico desta doença. Estas informações possibilitaram a adoção de medidas de controle em nível de búfala e/ou rebanho, podendo também ser útil para definição de políticas regionais no controle da mastite que vem trazendo grandes prejuízos para a cadeia leiteira bubalina. Essas medidas de controle poderão trazer melhorias no sistema produtivo, com o aumento da produção dos animais e melhoria da qualidade do leite, além da possibilidade de beneficiar os laticínios, com melhor rendimento na fabricação dos derivados, e ainda maior segurança alimentar para o consumidor final.

O objetivo deste estudo foi determinar a presença dos patógenos causadores da mastite em rebanhos de búfalas, correlacionar os resultados com os índices de qualidade de leite, avaliar o perfil de suscetibilidade dos microrganismos aos principais antibióticos utilizados no controle da mastite, e correlacionar os fatores de risco com a presença da mastite nas propriedades.

\section{Importância da mastite para a bubalinocultura}

Segundo Gonçalves (2008) a produtividade de búfalas no Brasil é constituído de valores ainda muito baixos, girando em torno de 4,9 e 5,2 $\mathrm{kg} / \mathrm{búfala/dia}$. Na Itália são registradas médias de aproximadamente $13 \mathrm{~kg}$ litros de leite/animal/dia (FAPRI, 2015).

Keefe (2012) relatou que a mastite é a principal doença infecciosa, e que traz grandes perdas na produtividade individual, e uma das possibilidades para os índices de produção individual das búfalas serem abaixo do esperado, pode estar correlacionada com a presença desta doença nos rebanhos de bubalinos do Brasil. A mastite não está relacionada somente às perdas econômicas, mas também está associada com a saúde pública, devido à presença de agentes que podem transmitir doenças aos seres humanos, resíduos de antibióticos no leite, e a presença de bactérias resistentes que podem ser propagadas na comunidade (De Vliegher et al., 2012). De acordo com Cunha et al. (2006) a mastite ocasiona prejuízos econômicos, ocasionados pela redução da produção e alteração dos principais componentes do leite. Além disso, ocorre diminuição da vida produtiva dos animais, comprometendo os quartos mamários. Segundo Silva \& Nogueira (2010) a mastite bovina é a doença de maior impacto para a bovinocultura no Brasil, a qual reduz a produção e qualidade do leite.

Por falta de informações sobre a espécie bubalina, utilizam-se para o controle da mastite as mesmas técnicas de criação e manejo indicadas para os bovinos (Carvalho et al., 2007).

Segundo García (2014) fica evidente a necessidade da realização de pesquisas visando obter conhecimento das reais características do leite de búfalas criadas em diferentes regiões do país e do mundo, com soluções que possam ser adotadas como medidas de controle de mastites, evitando sérios prejuízos aos produtores e consumidores de produtos de leite de búfala.

\section{A mastite e seu impacto econômico na cadeia produtiva do leite}

Como há uma escassez de estudos sobre o impacto econômico da mastite em rebanhos bubalinos, para ilustração das perdas ocorridas com esta doença fez-se um pequeno levantamento bibliográfico da mesma em rebanhos bubalinos e também bovinos. 
Taraphder et al. (2006) estudaram o custo da mastite em rebanhos de búfalas da raça Murrah, na Índia. Seus resultados apontaram que se gastou em média cerca de US\$ 209,86 para cada tratamento de caso de ocorrência da mastite. As búfalas mais velhas eram mais suscetíveis à mastite, necessitando de tratamento por um período relativamente maior. Houve uma queda na produção de leite de $46,91 \mathrm{~kg}$ durante o período que o animal estava com mastite, e a produção de leite em 305 dias de lactação foi significativamente afetada pela ocorrência de mastite.

De acordo Tozzetti et al. (2008) a mastite bovina tem sido apontada como a principal doença que afeta os rebanhos leiteiros no mundo inteiro, causando sérios prejuízos econômicos tanto ao produtor de leite quanto à indústria de laticínios. Segundo Keefe (2012) a mastite é considerada um dos principais fatores de risco para o sistema de produção leiteiro, sendo responsável por perdas econômicas expressivas em países desenvolvidos, apesar das diversas pesquisas e medidas preventivas estabelecidas. Além dos impactos negativos na indústria, a mastite causa de perdas econômicas aos produtores de leite pela redução na produção leiteira, na piora na qualidade do leite, consequente em alguns casos penalidade no preço pago, descarte de leite com resíduos de antibióticos, o aumento do uso de antibióticos para tratamentos, mão de obra e serviços veterinários (Lopes et al., 2012, Oviedo-Boyso et al., 2007). Segundo Hogeveen et al. (2011), a mastite pode diminuir a capacidade de produção de leite do tecido secretor mamário de forma irreversível, o que consequentemente reduz a média de produção de leite por animal na próxima lactação e, em casos mais graves, o descarte de animais ou mesmo o óbito dos animais infectados.

Os animais infectados terão uma alteração dos componentes do leite, com aumento no número de células somáticas, o que influenciará na menor vida de prateleira dos produtos (Losinger, 2005). Sendo assim, a CCS está diretamente relacionada com o rendimento de derivados lácteos (Lopes et al., 2012). Halasa et al. (2009) destacaram que esta alteração na qualidade do leite e redução da produção representa os maiores problemas econômicos causados pela mastite na indústria leiteira. De acordo com Souza et al. (2010), em seus estudos realizados em propriedades brasileiras, para estimar os custos da mastite subclínica, apresentaram resultados de perda de 4,6 bilhões de litros de leite, o que representaria aproximadamente 2,3 bilhões de reais levando-se em conta os dados de produção do ano de 2009.

$\mathrm{Na}$ Holanda, estima-se que as perdas econômicas devido à mastite clínica e subclínica variam entre $€ 17$ e $€ 198 /$ vaca/ano (Hogeveen et al., 2011). Em média, o custo total de um caso de mastite clínica causada por Streptococcus spp., baseado no tratamento com antimicrobiano intramamário, durante três dias, foi de 196 dólares, enquanto para o micro-organismo $S$. aureus foi de 255 dólares (Losinger, 2005).

\section{Prevalência da mastite em rebanhos de bubalinos}

De acordo com Pieterse \& Todorov (2010), a mastite é uma reação inflamatória na glândula mamária. Segundo Blood \& Studdert (1999), a doença é uma reação inflamatória da glândula mamária, cuja nomenclatura originou se do grego masto- glândula mamária e itis - inflamação. A mastite é consequência da interação de fatores relacionados ao animal, patógenos e ambientes. Esta se caracteriza em um processo inflamatório da glândula mamária causadas por agressões físicas, químicas, térmicas ou microbianas (Brito et al., 2000). A mastite ainda pode ser definida como uma invasão da glândula mamária predominantemente por microrganismos, que acarretarão uma inflamação no tecido mamário (Notebaert \& Meyer, 2006).

A mastite pode ocorrer de forma clínica ou subclínica. A forma clínica que se apresenta com sinais evidentes, tais como, edema, hipertermia, endurecimento e dor da glândula mamária e/ou aparecimento de grumos, pus ou alterações das características do leite. Já a mastite subclínica, se caracteriza por alterações na composição do leite. Entre as principais alterações destacam-se o aumento da contagem de células somáticas (CCS), o aumento dos teores de $\mathrm{Cl}$ e de $\mathrm{Na}$, proteínas séricas e diminuição do percentual de caseína, gordura, sólido total e lactose do leite (Tozzetti et al., 2008). Entre todos os efeitos causados pela mastite é de extrema importância o impacto desta doença na redução da produção leiteira, chegando a muitos casos tornar os quartos mamários afetados improdutivos (Tozzetti et al., 2008).

A infecção da glândula mamária ocorre majoritariamente por invasão dos microrganismos pelo canal do teto, e prossegue à 
cisterna da glândula. Esta invasão ocorre geralmente durante a ordenha, pelo contato das mãos do ordenhador ou outros materiais contaminados, podendo, no entanto ocorrer quando os animais estão em ambientes contaminadas, durante o período entre as ordenhas, quando o canal dos tetos pode permanecer abertos durante um período de uma a duas horas após a ordenha, o que facilita a penetração dos microrganismos (Aires, 2010).

Os microrganismos causadores de mastite clínica e subclínica são classificados em contagiosos e ambientais, sendo que esta classificação é feita de acordo com o modo de transmissão destes patógenos no rebanho. Os patógenos contagiosos são mais adaptados ao animal e tem maior chance de causar infecções subclínicas, enquanto os patógenos ambientais são considerados oportunistas, geralmente causando distúrbios graves de infecções intramamárias (Schukken et al., 2009). Os microrganismos contagiosos são caracterizados pela transmissão entre os animais, pelo contato com equipamentos contaminados ou através das mãos contaminadas do ordenhador, enquanto os ambientais são caracterizados pela transmissão do ambiente para a vaca (Bradley and Green, 2000).

Os principais patógenos contagiosos causadores de mastite em bovinos são Staphylococcus aureus e Streptococcus agalactiae. Os patógenos ambientais são aqueles presentes em fezes, solo e estalagem dos bovinos, os mais comuns são Streptococcus uberis, Streptococcus dysgalactiae, Eschererichia coli e Enterococcus spp. (Talbot and Lacasse, 2005).

As bactérias $S$. aureus, $S$. agalactiae, $S$. dysgalactiae e $S$. uberis normalmente causam maiores danos ao úbere que outros patógenos causadores de mastite, e por isto são denominados patógenos principais ou maiores (Reyher et al., 2012). Entre os agentes causadores da mastite mais frequentemente isolados, são $S$. aureus e $S$. agalactiae, responsáveis por, aproximadamente, $\quad 90 \%$ das infecções intramamárias dos rebanhos de bovinos leiteiros.

Medeiros et al. (2013) observaram em búfalas criadas nos estados do Nordeste brasileiro, uma incidência de mastite subclínica em 17,4\% e uma incidência de 3,37\% de mastite clínica. Nos casos de mastite subclínica, os gêneros mais prevalentes foram o Staphylococcus spp. (23,8\%), seguido pela Corynebacterium spp.
$(11,7 \%)$ e Gram bactérias negativas $(9,0 \%)$. Nos casos de mastite clínica, as bactérias do gênero Staphylococcus spp. estavam presentes em 42,2\% das amostras, seguido por Corynebacterium spp. $(11,3 \%)$ e Bactérias Gram negativas $(5,6 \%)$. Kapronezai et al. (2005) avaliaram 262 amostras de leite de fêmeas bubalinas, primíparas e pluríparas, de propriedades no estado de São Paulo. Os resultados observados através de análises microbiológicas foram uma incidência de $24,4 \%$ da mastite nos rebanhos, sendo que o Staphylococcus spp. estava presente em 11,8\% das amostras, Corynebacterium spp. 7,3\%, Streptococcus spp. 3,1\% e com crescimento de microrganismos em associações 1,2\%. Oliveira et al. (2004) analisaram 196 amostras de leite procedentes de 49 búfalas em cinco propriedades rurais, no Estado de Pernambuco. Das amostras analisadas $139(70,9 \%)$ foram positivas ao exame microbiológico, isolando-se $76(55 \%)$ amostras de Staphylococcus spp., sendo 18 (13\%) de Staphylococcus coagulase positiva e 58 (42\%) Staphylococcus coagulase negativa. Isolaram-se também 25 amostras de bastonetes (18\%) Gram negativos, oito (6\%) Streptococcus spp. e três $(2,2 \%)$ de Micrococcus spp. em culturas puras ou em associação, além de 45 amostras $(32,4 \%)$ de Bacillus spp. Cunha et al. (2006) observaram a frequência de agentes bacterianos envolvidos nos processos inflamatórios clínicos e subclínicos da glândula mamária em 128 búfalas, no Estado do Rio Grande do Norte. Os resultados foram que sete $(5,47 \%)$ apresentaram mastite clínica, e foram detectados 53 búfalas com mastite subclínica, totalizando $81(15,82 \%)$ quartos infectados. As bactérias prevalentes foram o Staphylococcus spp., em 48,38\% das amostras e o Streptococcus spp., presente em 15,05\% nas amostras de leite.

Langoni et al. (2001) estudaram a etiologia da mastite em amostras de leite provenientes de 61 búfalas da raça Murrah com mastite subclínica. Entre154 amostras de leite positivas ao CMT observou-se que $83 \quad(53,9 \%)$ apresentaram crescimento bacteriano, enquanto $71(46,1 \%)$ mostraram-se negativas. Os microrganismos isolados em cultura pura e em associação foram: Corynebacterium bovis $(\mathrm{n}=26 ; 31,3 \%)$, Staphylococcus epidermidis $(\mathrm{n}=25 ; 30,1 \%)$, Streptococcus agalactiae $\quad(\mathrm{n}=22 ; \quad 26,5 \%)$, Staphylococcus aureus $(\mathrm{n}=4 ; 4,8 \%)$, Acinetobacter calcoaceticus $(\mathrm{n}=2 ; 2,4 \%)$, Pasteurella multocida $(\mathrm{n}=2 ; 2,4 \%)$ e Bacillus $\mathrm{spp}$ $(\mathrm{n}=2 ; 2,4 \%)$. 
Silva et al. (2014) avaliaram a prevalência e a etiologia da mastite subclínica em búfalas da raça Jafarabadi, no município de Sales de Oliveira-SP. Dos 190 quartos mamários avaliados, 8,95\% apresentaram mastite subclínica, isolando o Staphylococcus spp. em 7 amostras (3,68\%), Streptococcus dysgalactiae em 3 amostras (1,58\%), Streptococcus $\alpha$-hemolítico em 2 (1,05\%), Bacillus spp em 2 amostras (1,05\%), Corynebacterium spp, Streptococcus spp e Nocardia spp em $0,53 \%$ das amostras. Pizauro et al. (2014) avaliaram a contagem de células somáticas, a prevalência e a etiologia da mastite bubalina, nas estações seca e chuvosa, em 1.042 amostras de leite de búfalas da raça Murrah, no município de Analândia, no Estado de São Paulo. As amostras de leite analisadas apresentaram CCS média de 137.720 células/mL, no período seco, e 190.309 células/mL, no período chuvoso, constatando que a frequência de isolamentos não foi influenciada significativamente pela estação do ano. Os principais patógenos isolados durante o período seco foram Staphylococcus coagulase negativa $(38,4 \%)$, Streptococcus agalactiae (28,8\%) e Bacillus spp. (7,56\%). No período chuvoso Corynebacterium spp. (23,5\%), Streptococcus spp. (32,3\%) e Streptococcus agalactiae $(9,24 \%)$ foram os principais patógenos isolados. Almeida (2014) pesquisaram sobre o gênero Staphylococcus, em 160 amostras de leite de búfala de uma propriedade localizada no município de Analândia, no Estado de São Paulo. Os resultados demonstraram que nenhuma búfala apresentou sinais clínicos de mastite, mas 32 quartos mamários apresentaram mastite subclínica com reação positiva ao CMT, e foram isoladas 22 estirpes de Staphylococcus aureus, o que correspondeu a $13,7 \%$ das amostras.

Silva et al. (2014) pesquisaram a ocorrência de mastite em 87 búfalas, no Estado do Pará, em diferentes fases de lactação, mantidas em sistema de criação extensivo. Dos 348 quartos mamários examinados, $89,4 \%$ não reagiram ao teste de CMT e 5,46\% reagiram, e ainda $2,87 \%$ dos quartos mamários apresentavam mastite clínica. No entanto, do total das amostras examinadas $24,4 \%$ apresentaram crescimento bacteriano, esta porcentagem maior que a encontrada no teste de CMT. Nas amostras reagentes ao CMT, o Streptococcus spp. foi o patógeno isolado em maior percentual (15,79\%), seguido por Staphylococcus aureus e Staphylococcus intermedius $(5,26 \%)$. Das amostras não reagentes ao CMT houve um crescimento bacteriano em
24,8\% das amostras, sendo Staphylococcus coagulase negativa $(12,9 \%)$ o agente mais presente, seguido por S. intermedius (3,90\%), S. aureus $(2,25 \%)$, Streptococcus agalactiae $(2,25 \%)$ e Streptococcus spp. (1,30\%). Concluíram que a ocorrência de mastite foi baixa nos rebanhos estudados, e que o CMT não demonstrou eficiência no diagnóstico da infecção intramamária, devendo sempre ser associado ao exame microbiológico.

\section{Particularidades das respostas de búfalas frente à mastite}

De acordo com Sollecito et al. (2011) algumas particularidades relacionadas a características anatômicas do úbere e tetos, imunologia da glândula mamária e composição do leite de búfalas podem conferir maior resistência contra a mastite. Conforme Uppal et al. (1994) essas características incluem maior concentração de pigmentos de melanina, canal do teto com epitélio estratificado queratinoso mais espesso que o observado na vaca, camada muscular do esfíncter ao redor do canal do teto mais espessa e organizada, com maior tônus, mais rica em vasos sanguíneos e fibras nervosas, e ainda um diâmetro menor do lúmen do canal do teto. Segundo Kapronezai (2004) há também uma maior atividade da enzima lactoperoxidase e maior concentração de lactoferrina no leite conferindo uma atividade antibacteriana mais eficiente do que em bovinos.

Lazzari et al. (2014) avaliaram em vacas e em búfalas submetidas à mastite induzida por inoculação de Staphylococcus aureus, a concentração da citocina pró-inflamatória interleucina-1 $\beta$ (IL-1 $\beta$ ), a contagem de células somáticas (CCS) e a correlação destas com alguns parâmetros da resposta local e sistêmica à inflamação, concluiu que vacas e búfalas apresentaram elevação na CCS, elevação na concentração de IL-1 $\beta$ no leite e resposta localizada e sistêmica à inflamação, porém as búfalas demonstram uma elevação mais rápida de IL-1 $\beta$, mas as vacas alcançam uma concentração mais elevada. Na espécie bovina, há correlação entre a concentração da IL-1 $\beta$, CCS e severidade da mastite, o que não ocorreu nas búfalas, em consequência destes resultados as búfalas desenvolveram um processo inflamatório mais rápido e menos severo que as vacas, o que antecipou o restabelecimento dos parâmetros utilizados para avaliar a resposta à inflamação. 


\section{Alterações na composição físico-química do leite de búfalas em decorrência da mastite}

Assim como o leite oriundo de bovinos o leite de bubalinos também tem a composição e qualidade alteradas quando oriundo de animais com mastite (Cerón-Muñoz et al., 2002), com intensidade que depende da resposta inflamatória do animal, dos fatores de virulência do agente etiológico da doença e da extensão do tecido afetado (Zafalon et al., 2005). A resposta imune pode variar entre diferentes agentes patogênicos e cada agente patogênico induz alterações específicas no leite (Bannerman et al., 2004, Leitner et al., 2006). Os leucócitos correspondem a 98 a $99 \%$ das células encontradas no leite. $\mathrm{O}$ processo inflamatório provoca a liberação de substâncias químicas devido à ação dos agentes patogênicos e da destruição de tecido secretor, o que induz a passagem de células brancas do sangue para o interior da glândula. Estas células têm a função de combater os agentes patogênicos (Philpot and Nickerson, 1991). No que se refere ao controle de qualidade, o aumento da contagem de células somáticas (CCS) é o principal marcador para a detecção e diagnóstico de mastite (Viguier et al., 2009).

Segundo Brito et al. (2001) a principal causa do aumento da contagem de células do leite é resposta inflamatória da glândula mamária, que na maioria dos casos, é resultado de uma infecção bacteriana, resultando em vasodilatação, e diversas substâncias do sangue passam junto com os leucócitos para o leite. Entre essas estão íons de cloro e sódio, que deixam o leite com sabor salgado. Devido às lesões no tecido mamário, as células secretoras se tornam menos eficientes, isto é, com menor capacidade de produzir e secretar o leite. Isso explica a perda de qualidade e a redução na produção do animal (Brito et al., 2001).

De acordo com Galiero \& Morena (2000) a perda de produção se dá após a invasão, que ocasiona intensa migração de leucócitos para o quarto mamário afetado com objetivo de controlar e eliminar a infecção. Consequentemente, uma das alterações encontradas no leite de animais com mastite é o aumento do número de células somáticas (CCS), representadas pelos leucócitos (glóbulos brancos do sangue) e células epiteliais provenientes da esfoliação dos ácinos galactóforos do úbere, cisterna mamária e cisterna do teto e são eliminadas no leite durante o curso normal da lactação.

Cerón-Muñoz et al. (2002) relataram que a CCS, sendo uma expressão direta da severidade do processo inflamatório, é um parâmetro usual para avaliação da saúde do úbere com relação à qualidade do leite e monitoramento de programas de controle de qualidade, e que búfalas com elevada CCS apresentam redução da produção de leite.

Segundo Müller (2002) a alteração da CCS no leite de animais individuais ou de tanque é uma ferramenta valiosa na avaliação do nível de mastite subclínica no rebanho, na estimativa das perdas quantitativas e qualitativas de produção do leite e derivados, como indicativo da qualidade do leite produzido na propriedade e para estabelecer medidas de prevenção e controle da mastite.

Tripaldi et al. (2003) realizaram uma pesquisa no território central da Itália, país no qual o leite de búfalas tem grande importância na produção de mussarela. Observaram valores médios de 221.000 células $/ \mathrm{mL}$, para a qual o limite de CCS aceitável é de 200 mil células/mL, naquele país.

De acordo com Machado et al. (2000) a mensuração das células somáticas permite a quantificação do grau de infecção da glândula mamária, e sua avaliação periódica da CCS do leite do tanque do rebanho permite a determinação da incidência média de mastite no rebanho. Ribas et al. (2014) avaliaram em 1.950.034 amostras de leite de bovinos, o comportamento do ECS (escore de células somáticas) e suas relações com os teores de gordura, proteína, lactose e sólidos totais do leite cru de amostras de tanques., Os resultados apontaram que altas CCS influenciaram a composição do leite, afetando sua qualidade, alterando a permeabilidade dos vasos sanguíneos da glândula mamária e reduzindo a secreção dos componentes do leite sintetizados (proteína, gordura e lactose) pela ação direta dos patógenos ou de enzimas.

Medeiros et al. (2011) estudaram o perfil de células somáticas na mastite subclínica em búfalas leiteiras no Nordeste do Brasil, analisando 1896 amostras de leite, em propriedades nos Estados de Pernambuco, Alagoas, Bahia e Ceará. As amostras positivas ao teste de CMT e exames microbiológicos apresentaram CCS entre 280.000 a 401.000 
$\mathrm{cel} / \mathrm{mL}$ com mediana de $328.000 \mathrm{cel} / \mathrm{mL}$, levando a conclusão que valores de CCS acima de $280.000 \mathrm{cel} / \mathrm{mL}$ é um indicativo de infecção da glândula mamária.

Pizauro et al. (2014) estudaram amostras de leite com resultado positivo em exames microbiológicos, as quais apresentaram CCS média de 137.720 células $/ \mathrm{mL}$, no período seco, e 190.309 células/mL, no período chuvoso. As variações na CCS de amostras de leite com resultados positivos em testes microbiológicos recolhidos durante os períodos de seca e chuvosa pode estar relacionada com a fase de infecção e do tipo do isolado microrganismo.

Bansal et al. (2007) pesquisaram em 101 búfalos da raça Murrah, a composição físicoquímica do leite, contagem de células somáticas (CCS) em animais saudáveis e com mastite. Seus resultados demonstraram que búfalas sem mastites tinham em média de 5,13\%, 3,44\%, $5,78 \%$ e 9,84, respectivamente para gordura, proteína, lactose e extrato seco desengordurado, enquanto que búfalas com a presença de microrganismos causadores da mastite tinham $5,21 \%, 3,26 \%, 5,51 \%$ e $9,39 \%$, respectivamente para gordura, proteína, lactose e extrato seco desengordurado, demonstrando que em todas as variáveis medidas sofreram alterações significativas. A variável CCS indicou mudanças significativas, que em animais saudáveis continham 61.000 cels $/ \mathrm{mL}$, enquanto que em animais infectados estava em torno de 593.000 cels $/ \mathrm{mL}$ de leite.

Almeida (2014) estudaram em 592 búfalas, em diferentes fases de lactação, as alterações físicoquímicas que ocorrem no leite devido à mastite. Seus resultados demonstraram que a diferença na produção de leite entre as búfalas sem mastite e búfalas com infecção intramamária foi de 1,3 litros dia, representando uma queda de $22,03 \%$ na produção leiteira Para a porcentagem de gordura contida no leite diminui de $6.6 \%$ de búfalas saudáveis para $4.6 \%$ em búfalas mastíticas. A proteína de $4.8 \%$ para $4.0 \%$, lactose de $5.1 \%$ para $3.9 \%$ e extrato seco desengordura de $9.9 \%$ para 8.0\% em búfalas com infecção intramamária.

Cerón-Muñoz et al. (2002) avaliaram a correlação da CCS sobre à produção diária de leite, porcentagem de gordura do leite, proteína, lactose e sólidos totais, em 222 búfalas, da raça Murrah, no Estado de São Paulo. Os resultados demonstraram que houve uma correlação entre CCS, lactose e produção de leite negativo durante todos os meses de lactação, causando prejuízos para os produtores de leite de búfala. Por isso os testes para a detecção de mastite devem ser feitos nos rebanhos de búfalos produtores de leite, a fim de melhorar a qualidade higiênica de leite, e assim, melhorar a qualidade de produtos oferecidos no mercado.

\section{Sensibilidade de patógenos causadores de mastite em búfalas aos antimicrobianos}

Segundo Brito et al. (1998) e Brito et al. (2001) a resistência aos antimicrobianos é uma das principais preocupações atualmente no controle da mastite, e que vêm se revelando ser crescente nos últimos anos em bovinos leiteiros. Langoni et al. (2001) observaram pelos seus resultados de sensibilidade antimicrobiana, em teste in vitro, que o cloranfenicol com $88 \%, 92,3 \%$ e $90,3 \%$ de sensibilidade, a gentamicina $80 \%, 96,2 \%$ e $95,5 \%$, a oxacilina $76 \%, 84,6 \%$ e $95,5 \%$, foram as drogas de melhor eficácia para o controle dos patógenos Corynebacterium bovis, Staphylococcus epidermidis e Streptococcus agalactiae, que foram os microrganismos isolados com maior frequência em suas amostras em búfalas acometidas pela mastite.

Vianni \& Lázaro (2003) estudaram o perfil de susceptibilidade a antimicrobianos em cocos Gram-positivos catalase negativos, em 21 amostras de Lactococcus garvieae e 6 de Enterococcus gallinarum, isoladas do leite de búfalas com mastite subclínica, em seis rebanhos bubalinos localizados no Estado do Rio de Janeiro. Os resultados evidenciaram que $\mathrm{o}$ Lactococcus garvieae, o antimicrobiano mais eficiente foi nitrofurantoína com 85,7\% de sensibilidade, seguido da cefotaxima $(61,9 \%)$, vancomicina $(52,4 \%)$, norfloxacina $(47,6 \%)$ e cefalotina $(47,6 \%)$. A maior resistência foi desenvolvida frente à penicilina e ampicilina, com $95,24 \%$. A susceptibilidade das amostras de Enterococcus gallinarum à frente eritromicina e à gentamicina foram de 33,3\% de sensibilidade para ambos. Quanto à resistência foram de $100 \%$ com relação à vancomicina e tetraciclina, seguindo-se cloranfenicol, penicilina, ampicilina, cefoxitina, cefalotina, cefotaxima, norfloxacina e nitrofurantoína, todas evidenciando uma resistência de 83,33\% das amostras testadas.

Cunha et al. (2006) avaliaram o perfil de sensibilidade in vitro para diferentes patógenos causadores de mastite em búfalas frente a alguns antibióticos. Os resultados demonstraram que a 
gentamicina foi o antibiótico com maior percentual de eficácia $(98,0 \%)$, seguida pelo florfenicol $(93,9 \%)$ e enrofloxacina $(90,9 \%)$. A penicilina $(65,7 \%)$ e a tetraciclina $(58,6 \%)$ foram às drogas que apresentaram a menor eficácia no controle dos patógenos das amostras isoladas no estudo.

Bonna et al. (2007) pesquisaram os patógenos do gênero Staphylococcus coagulase-negativos (SCN) contidos no leite de búfalas, e sua resistência frente a drogas antibacterianas. Os resultados demonstraram que há um maior padrão de resistência frente aos $\beta$-lactâmicos, penicilina, amoxicilina, ampicilina (média 51,8\%), e um menor padrão de resistencia frente a cefalotina, vancomicina, cefoxitima e a gentamicina, com $0 \%$ de resistência.

Pizauro et al. (2014) estudaram a resistência aos antimicrobianos, em dos microrganismos isolados de suas amostras de leite de búfalas. Os resultados obtidos, demonstrados através do antibiograma, em $94,0 \%$ das bactérias isoladas foram sensíveis a gentamicina, $88,0 \%$ ao ceftiofur, $88,0 \%$ aos cefoperazona, $84,3 \%$ de ampicilina, $78,3 \%$ aos oxacilina, $74,7 \%$ de penicilina, $71,1 \%$ aos enrofloxacina, $67,5 \%$ a $60,2 \%$ e neomicina para sulfametoxazol / trimetoprim.

Almeida (2014) pesquisou em 22 estirpes de Staphylococcus aureus, isoladas de leite de búfalas, a sensibilidade das amostras frente a alguns antimicrobianos. Os antibióticos cloranfenicol, rifampicina, cefepime, oxacilina, ciprofloxacina, gentamicina, tetraciclina. Foram $100 \%$ eficazes no controle as estirpes das amostras. Outros antimicrobianos tiveram resultados diferentes, como a clindamicina (96,9\%), a vancomicina $(96,9 \%)$, o cotrimazol $(93,8 \%)$. Verificaram ainda que este patógeno demonstrou alta resistência frente à penicilina, com apenas $31,3 \%$ de sensibilidade, eritromicina $(43,8 \%)$, e uma estirpe apresentou-se multirresistente.

Silva et al. (2014) realizaram o antibiograma em amostras de leite de búfalas, em propriedades no Estado do Pará. Observaram que 94,1\% dos isolados de SCN foram sensíveis à gentamicina, $92,2 \%$ à cefalotina e $90,2 \%$ à cefoxitina; $47,1 \%$ apresentaram resistência à penicilina G. Dos isolados de Staphylococcus spp. coagulase positiva (S. aureus e S. intermedius), $100 \%$ foram sensíveis à amoxicilina e cefalotina, 95,2\% à cefoxitina, oxacilina e sulfazotrim, dos isolados apresentaram sensibilidade intermediária de $61,9 \%$ e $47,6 \%$ à eritromicina e estreptomicina, respectivamente. Os isolados de Streptococcus spp. foram $90 \%$ sensíveis à amoxicilina, ampicilina e sulfazotrim; $80 \%$ sensíveis à cefalotina, eritromicina, penicilina $G$ e tetraciclina. Em relação aos isolados de $S$. agalactiae, $100 \%$ foram sensíveis à amoxicilina e tetraciclina; $87,5 \%$ à ampicilina, cefalotina e sulfazotrim.

Guimarães et al. (2012) avaliaram a suscetibilidade de isolados de Staphylococcus spp. obtidos de casos de mastite em vacas $(\mathrm{n}=30)$ e búfalas $(\mathrm{n}=30)$, aos principais antimicrobianos. Os Staphylococcus spp. presentes nas amostras de leite bubalinas apresentaram o percentual de sensibilidade aos antimicrobianos de 100,0\% para enrofloxacina, cefalexina e gentamicina; $90,0 \%$ para eritromicina, $86,7 \%$ para tetraciclina, $83,3 \%$ para estreptomicina, $80,0 \%$ para penicilina e neomicina e $76,7 \%$ para sulfazotrim e ampicilina. Vinte e quatro isolados (40,0\%), 14 bubalinas e dez vacas, apresentaram sensibilidade a todos os antimicrobianos testados. Das quinze amostras identificadas como S. aureus, seis $(40,0 \%)$ apresentaram sensibilidade a todos os antimicrobianos.

Prichula et al. (2013) avaliaram a diversidade e o perfil de suscetibilidade a antimicrobianos de enterococos isolados de amostras de leite cru de búfalas no Sul do Brasil. Observaram que a maioria dos enterococos era sensível aos antimicrobianos testados, entretanto, 13,9\% apresentaram perfil de resistência a nitrofurantoína, $12,7 \%$ a tetraciclina, $1,3 \%$ a eritromicina, $1,3 \%$ a norfloxacina, $1,3 \%$ a cloranfenicol e $1,3 \%$ a estreptomicina, concluindo que o leite bubalino apresentou a presença de E. faecalis multirresistentes, servindo de alerta para a importância da cadeia alimentar na disseminação de resistência aos antimicrobianos de uso clínico fora de ambientes nosocomiais.

\section{Considerações Finais}

Vários trabalhos relataram a ocorrência de quadros de mastite clínica e subclínica em búfalas, onde estavam presentes bactérias dos gêneros Staphylococcus spp., Streptococcus spp, Corunebacterium spp., Acinetobacter spp., Pasteurela spp. e Lactococcus spp. e as leveduras Cândida spp., Aspergilus spp. e Penicilium spp, trazendo grande impacto sanitário e econômico 
para a atividade leiteira. Para obter sucesso no tratamento das fêmeas com mastite deve-se avaliar de forma correta a inclusão substância bactericida/bacteriostática à prática de tratamento para otimizar a eficiência da droga escolhida e minimizar a presença de resíduo de medicamentos no leite.

\section{Referências Bibliográficas}

Aires, T. A. C. P. 2010. Mastites em Bovinos: caracterização etiológica, padrões de sensibilidade e implementação de programas de qualidade do leite em explorações do Entre-Douro e Minho. Faculdade de Medicina Veterinária Universidade Técnica de Lisboa, Lisboa.

Almeida, C. C. 2014. Isolation and identification of antimicrobial resistant staphylococcus aureus isolated from buffalo milk samples bubalino. Revista Brasileira de Higiene $e$ Sanidade Animal, 8, 1-4.

Bannerman, D. D., Paape, M. J., Lee, J.-W., Zhao, X., Hope, J. C. \& Rainard, P. 2004. Escherichia coli and Staphylococcus aureus elicit differential innate immune responses following intramammary infection. Clinical and Diagnostic Laboratory Immunology, 11, 463-472.

Bansal, B. K., Hamann, J., Lind, O., Singh, S. T. \& Dhaliwal, P. S. 2007. Somatic cell count and biochemical components of milk related to udder health in buffaloes. Italian Journal of Animal Science, 6, 1035-1038.

Bonna, I. C. F., Santos, A. P. V., Teixeira, G. N. \& Vieira-da-Motta, O. 2007. Staphylococcus coagulase-negativos resistentes a drogas isolados de leite de búfalas (Bubalus bubalis). Revista Brasileira de Ciência Veterinária, 14, 117-121.

Bradley, A. J. \& Green, M. J. 2000. A study of the incidence and significance of intramammary enterobacterial infections acquired during the dry period. Journal of Dairy Science, 83, 1957-1965.

Brito, J. R. F., Brito, M. A. V. P. \& Verneque, R. S. 2000. Contagem bacteriana da superfície de tetas de vacas submetidas a diferentes processos de higienização, incluindo a ordenha manual com participação do bezerro para estimular a descida do leite. Ciência Rural, 30, 847-850.
Brito, M. A. V. P., Brito, J. R. F., Silva, M. A. \& Carmo, R. A. 2001. Concentraçäo mínima inibitória de dez antimicrobianos para amostras de Staphylococcus aureus isoladas de infecçäo intramamária bovina. Arquivo Brasileiro de Medicina Veterinaria $e$ Zootecnia, 53, 531-537.

Brito, M. A. V. P., Brito, J. R. F., Souza, H. M. \& Vargas, O. L. 1998. Avaliação da sensibilidade da cultura de leite do tanque para isolamento de agentes contagiosos da mastite bovina. Pesquisa Veterinária Brasileira, 18, $39-44$.

Carvalho, L. B., Amaral, F. R., Brito, M. A. V., Lange, C. C., Brito, J. R. \& Leite, R. C. 2007. Contagem de células somáticas e isolamento de agentes causadores de mastite em búfalas (Bubalus bubalis). Arquivo Brasileiro de Medicina Veterinaria e Zootecnia, 59, 242245.

Cerón-Muñoz, M., Tonhati, H., Duarte, J., Oliveira, J., Muñoz-Berrocal, M. \& JuradoGámez, H. 2002. Factors affecting somatic cell counts and their relations with milk and milk constituent yield in buffaloes. Journal of Dairy Science, 85, 2885-2889.

Cunha, A. P., Silva, L. B. G., Pinheiro Júnior, J. W., Silva, D. R., Oliveira, A. A. F., Silva, K. P. C. \& Mota, R. A. 2006. Perfil de sensibilidade antimicrobiana de agentes contagiosos e ambientais isolados de mastite clínica e subclínica de búfalas. Arquivos do Instituto Biológico, 73, 17-21.

De Vliegher, S., Fox, L. K., Piepers, S., McDougall, S. \& Barkema, H. W. 2012. Invited review: Mastitis in dairy heifers: Nature of the disease, potential impact, prevention, and control. Journal of Dairy Science, 95, 1025-1040.

FAPRI. 2015. Food and Agricultural Policy Research Institute. In: Database, W. A. O. (ed.) Food and Agricultural Policy Research Institute. Iowa State University and University of Missouri-Columbia Ames, IA, USA.

Galiero, G. \& Morena, C. 2000. The meaning of the somatic cell count in buffalo milk. Bubalus Bubalis, 6, 26-27.

Gonçalves, O. 2008. Características de criações de búfalos no Brasil e a contribuição do marketing no agronegócio bubalino. Faculdade de Zootecnia e Engenharia de 
Alimentos. Universidade de São Paulo, Pirassununga.

Guimarães, G., França, C. A., Krug, F. S., Peixoto, R. M., Krewer, C. C., Lazzari, A. M. \& Costa, M. M. 2012. Caracterização fenotípica, produção de biofilme e resistência aos antimicrobianos em isolados de Staphylococcus spp. obtidos de casos de mastite em bovinos e bubalinos. Pesquisa Veterinária Brasileira, 32, 1219-1224.

Halasa, T., Nielen, M., De Roos, A. P. W., Van Hoorne, R., De Jong, G., Lam, T. J. G. M., Van Werven, T. \& Hogeveen, H. 2009. Production loss due to new subclinical mastitis in Dutch dairy cows estimated with a test-day model. Journal of Dairy Science, 92, 599-606.

Hogeveen, H., Pyorala, S., Waller, K. P., Hogan, J. S., Lam, T., Oliver, S. P., Schukken, Y. H., Barkema, H. W. \& Hillerton, J. E. 2011. Current status and future challenges in mastitis research. NMC Annual Meeting Proceedings.

Kapronezai, J. 2004. Estudo de provas microbiológicas e celulares em amostras de leite provenientes de fêmeas bubalinas (Bubalus bubalis) no Estado de São Paulo. Medicina Vetrinária Preventiva e Saúde Animal. Universidade de São Paulo, São Paulo.

Kapronezai, J., Melville, P. \& Benites, N. R. 2005. Análise microbiológica, teste de Tamis e California Mastitis Test realizados em amostras de leite de fêmeas bubalinas pertencentes a rebanhos do Estado de São Paulo. Arquivo do Instituto Biológico de São Paulo, 72, 183-187.

Keefe, G. 2012. Update on control of Staphylococcus aureus and Streptococcus agalactiae for management of mastitis. Veterinary Clinics of North America: Food Animal Practice, 28, 203-216.

Langoni, H., Domingues, P. F., Mlero Filho, J. R. \& Baldini, S. 2001. Etiologia e sensibilidade bacteriana da mastite subclínica em búfalos (Bubalus bubalis). Ars Veterinária, 17, $213-$ 217.

Lazzari, A. M., Oliveira, M. V. S., Moreti, B., Guimarães, G., Krug, F., Noleto, G., Mesquita, A. J., Magalhães, K. G., Bocca, A. L. \& Neves, J. P. 2014. Produção de interleucina-1beta e severidade da mastite pós-inoculação de Staphylococcus aureus na glândula mamária de bovinos e bubalinos. Ciência Rural, 44, 1816-1822.

Leitner, G., Krifucks, O., Merin, U., Lavi, Y. \& Silanikove, N. 2006. Interactions between bacteria type, proteolysis of casein and physico-chemical properties of bovine milk. International Dairy Journal, 16, 648-654.

Lopes, M. A., Demeu, F. A., Rocha, C. M. B. M., Costa, G. M., Franco Neto, A. \& Santos, G. 2012. Avaliação do impacto econômico da mastite em rebanhos bovinos leiteiros. Arquivos do Instituto Biológico, 79, 477-483.

Losinger, W. C. 2005. Economic impact of reduced milk production associated with Johne's disease on dairy operations in the USA. Journal of Dairy Research, 72, 425432.

Machado, P. F., Pereira, A. R. \& Sarríes, G. A. 2000. Composição do leite de tanques de rebanhos brasileiros distribuídos segundo sua contagem de células somáticas. Revista Brasileira de Zootecnia, 29, 1883-1886.

Medeiros, E. S., Barbosa, S. B. P., Jatobá, R. B., Azevedo, S. S., Junior, J. W. P., Saukas, T. N., de Albuquerque, P. P. F. \& Mota, R. A. 2011. Perfil da contagem de células somáticas na infecção intramamária em búfalas na Região Nordeste do Brasil. Pequisa Veterinária Brasileira, 31, 219-223.

Medeiros, E. S., Freitas, M. F. L., Pinheiro Júnior, J. W., Saukas, T. N., Krewer, C. C., Santos, A. S., Costa, M. M. \& Mota, R. A. 2013. Bubaline mastitis etiology in Northeast of Brazil. Arquivo Brasileiro de Medicina Veterinária e Zootecnia, 65, 1891-1894.

Müller, E. E. 2002. Qualidade do leite, células somáticas e prevenção da mastite. In: Santos, G. T. (ed.) Simpósio sobre Sustentabilidade da Pecuária Leiteira na Região Sul do Brasil. Toledo, Paraná.

Notebaert, S. \& Meyer, E. 2006. Mouse models to study the pathogenesis and control of bovine mastitis. A review. Veterinary Quarterly, 28, 2-13.

Oliveira, M. V. V., Mota, R. A., Oliveira, A. A. F., Meirelles, F. S. \& Silva, F. F. 2004. Utilização do Whiteside Modificado e California Mastitis Test no diagnóstico da mastite subclínica em búfalas e sua relação 
com o exame microbiológico. Ciência Animal, 14, 39-45.

Oviedo-Boyso, J., Valdez-Alarcón, J. J., CajeroJuárez, M., Ochoa-Zarzosa, A., López-Meza, J. E., Bravo-Patino, A. \& Baizabal-Aguirre, V. M. 2007. Innate immune response of bovine mammary gland to pathogenic bacteria responsible for mastitis. Journal of Infection, 54, 399-409.

Philpot, W. N. \& Nickerson, S. C. 1991. Mastitis: counter attack.

Pieterse, R. \& Todorov, S. D. 2010. Bacteriocins: exploring alternatives to antibiotics in mastitis treatment. Brazilian Journal of Microbiology, 41, 542-562.

Pizauro, L., Silva, D., Santana, A., Clemente, V., Lara, G., Listoni, F., Vaz, A., Vidal-Martins, A., Ribeiro, M. \& Fagliari, J. 2014. Prevalence and etiology of buffalo mastitis and milk somatic cell count in dry and rainy seasons in a buffalo herd from Analândia, São Paulo State, Brazil. Arquivo Brasileiro de Medicina Veterinária e Zootecnia, 66, 1703-1710.

Prichula, J., Zvoboda, D. A., Pereira, R. I., Santestevan, N. A., Medeiros, A. W., Souza, M. A., Azevedo, P. A., Giordani, A. R. \& Frazzon, A. P. G. 2013. Perfil de suscetibilidade aos antimicrobianos e diversidade das espécies de enterococos isolados de leite cru de búfalas no Sul do Brasil. Revista Brasileira de Ciência Veterinária, 20, 104-109.

Reyher, K. K., Haine, D., Dohoo, I. R. \& Revie, C. W. 2012. Examining the effect of intramammary infections with minor mastitis pathogens on the acquisition of new intramammary infections with major mastitis pathogens-A systematic review and metaanalysis. Journal of Dairy Science, 95, 64836502 .

Ribas, N. P., Junior, P. R., de Andrade, U. V. C., Valotto, A. A., de Jesus, C. P. \& de Almeida, M. C. 2014. Escore de células somáticas e sua relação com os componentes do leite amostrados de tanque no estado do Paraná. Archives of Veterinary Science, 19, 14-23.

Schukken, Y. H., González, R. N., Tikofsky, L. L., Schulte, H. F., Santisteban, C. G., Welcome, F. L., Bennett, G. J., Zurakowski, M. J. \& Zadoks, R. N. 2009. CNS mastitis:
Nothing to worry about? Veterinary Microbiology, 134, 9-14.

Silva, M. V. M. \& Nogueira, J. L. 2010. Mastite: controle e profilaxia no rebanho bovino. Revista Científica Eletrônica de Medicina Veterinária, 3, 1-13.

Silva, N., Silveira, J. A. S., Oliveira, C. M. C., Mendonça, C. L., Albernaz, T. T., Sousa Guaraná, E. L., Silva Lima, D. H. \& Barbosa, J. D. 2014. Ocorrência de mastite em búfalas (Bubalus bubalis) criadas em sistema extensivo no estado do Pará, Brasil= Mastitis occurrence in buffaloes (Bubalus bubalis) extensively farmed in the state of Para, Brazil. Bioscience Journal, 30, 839-846.

Sollecito, N. V., Lopes, L. B. \& Leite, R. C. 2011. Sensibilidade antimicrobiana e microorganismos isolados de mastites em búfalos : Breve revisão. Revista Brasileira de Medicina Veterinária, 33, 18-22.

Talbot, B. G. \& Lacasse, P. 2005. Progress in the development of mastitis vaccines. Livestock Production Science, 98, 101-113.

Taraphder, S., Tomar, S. S. \& Gupta, A. K. 2006. Incidence, inheritance and economics of mastitis in an organised herd of Murrah buffaloes. The Indian Journal of Animal Sciences, 76, 4425.

Tozzetti, D. S., Bataier, M. B. N., Almeida, L. R. \& Piccinin, A. 2008. Prevenção, controle e tratamento das mastites bovinas-revisão de literatura. Revista Científica Eletrônica de Medicina Veterinária, 6, 1-7.

Tripaldi, C., Terramoccia, S., Bartocci, S., Angelucci, M. \& Danese, V. 2003. The effects of the somatic cell count on yield, composition and coagulating properties of Mediterranean buffalo milk. Asian Australasian Journal of Animal Sciences, 16, 738-742.

Vianni, M. C. E. \& Lázaro, N. S. 2003. Perfil de susceptibilidade a antimicr fil de susceptibilidade a antimicr fil de susceptibilidade a antimicrobianos em amostras de obianos em amostras de cocos Gram-positivos, catalase negativos, isoladas de mastite subclínica bubalina. Pequisa Veterinária Brasileira, 23, 47-51.

Viguier, C., Arora, S., Gilmartin, N., Welbeck, K. \& O'Kennedy, R. 2009. Mastitis detection: current trends and future perspectives. Trends in Biotechnology, 27, 486-493. 
Zafalon, L. F., Nader Filho, A., Oliveira, J. V. \& Resende, F. D. 2005. Comportamento da condutividade elétrica e do conteúdo de cloretos do leite como métodos auxiliares de diagnóstico na mastite subclínica bovina. Pesquisa Veterinária Brasileira, 25, 159-63.

\section{Article History:}

Received 6 October 2016

Accepted 18 October 2016

Available on line 16 November 2016

License information: This is an open-access article distributed under the terms of the Creative Commons Attribution License 4.0, which permits unrestricted use, distribution, and reproduction in any medium, provided the original work is properly cited. 